\title{
Democratização, justiça social e igualdade na avaliação de uma política afirmativa: com a palavra, os estudantes
}

Andreliza Cristina de Souza ${ }^{a}$
Mary Ângela Teixeira Brandalise

\section{Resumo}

Este artigo é parte de uma pesquisa de Mestrado concluída, cujo objetivo foi desvelar se a política de cotas de uma instituição de Ensino Superior paranaense, na percepção dos estudantes que a ela recorreram para ingresso nos cursos de Graduação, favorece ou possibilita a democratização do acesso e a promoção da igualdade e da justiça social. Os dados foram coletados por meio de questionário e analisados segundo a metodologia do Discurso do Sujeito Coletivo (DSC). Este texto traz uma breve discussão sobre política social, pública, afirmativa e de cotas. $\mathrm{Na}$ avaliação da política de cotas, três conceitos fundamentaram a discussão: democratização, igualdade e justiça social. Este estudo revelou que a política de cotas pode contribuir para a democratização do acesso e para a promoção da igualdade e da justiça social, desde que outras ações ou políticas sociais sejam desenvolvidas paralelamente na sociedade, a fim de garantir a todo cidadão o direito à igualdade e o direito à diferença.

Palavras-chave: Democratização. Igualdade. Justiça social. Política de cotas.

\section{Introdução}

Este artigo apresenta algumas reflexões sobre a avaliação de uma política de cotas implantada em uma instituição de ensino superior paranaense, a partir da percepção de estudantes que, por meio de tal política, ingressaram nos cursos de Graduação. O presente estudo traz, para o debate acadêmico, resultados de parte de uma pesquisa de Mestrado concluída em 2012, cujo propósito foi desvelar se a política afirmativa criada na instituição vem possibilitando a democratização do acesso e a promoção da justiça social e da igualdade.

a Universidade Estadual de Ponta Grossa - UEPG. Ponta Grossa, Paraná, Brasil.

Recebido em: 29 Ago., 2013

Aceito em: 22 Abr., 2014 
O debate sobre a política de cotas, na referida instituição, foi iniciado no ano de 2005, com ampla discussão na comunidade acadêmica dessa instituição, o qual culminou em uma proposta de reserva de vagas, em processo seletivo de vestibular, para candidatos oriundos de escolas públicas e candidatos negros oriundos de escolas públicas.

A aprovação dessa reserva de vagas deu-se por meio de resolução universitária, com reserva de $10 \%$ das vagas de cada curso de Graduação para candidatos oriundos de escola pública e 5\% das vagas de cada curso de Graduação para candidatos negros oriundos de escola pública. O prazo fixado pela resolução para reserva de vagas pela política de cotas foi definido para oito anos, abrangendo, portanto, o período de 2006 a 2013. Na proposta da política, ficou definido que, a cada ano, os limites mínimos de vagas fossem aumentados em 5\% para a cota de estudantes oriundos de escolas públicas e em 1\%, a cada ano, para estudantes negros oriundos de escolas públicas, de tal modo que, ao término do período estabelecido, $50 \%$ das vagas da instituição para acesso ao ensino superior pelo vestibular ocorressem pelo sistema de cotas.

Este texto está organizado em quatro seções: na primeira, faz-se uma breve discussão sobre os conceitos de política social, política pública, política afirmativa e política de cotas, a partir das ideias de alguns autores; na segunda, discutem-se os conceitos de democratização, justiça social e igualdade; a metodologia da pesquisa está explicitada na terceira parte, com ênfase no procedimento de análise de dados da metodologia do Discurso do Sujeito Coletivo (DSC). Para finalizar, são tecidas as considerações finais.

\section{Políticas sociais, públicas, afirmativas e de cotas: compreendendo conceitos}

A política de cotas é um tema que vem sendo bastante estudado nos últimos anos, nos âmbitos nacional e internacional. Celina Souza (2006) diz que, para melhor compreender uma área de conhecimento, sua origem e ontologia, é necessário entender sua trajetória, não sendo diferente com as políticas públicas.

A política pública, como área de conhecimento, teve seu surgimento nos Estados Unidos, concentrando seus estudos na ação dos governos. Na Europa, essa área surge como um desdobramento dos estudos baseados em teorias sobre o papel 
do Estado e, por consequência, do governo - produtor de políticas públicas por excelência.

Para melhor compreender o conceito de política, é necessário recorrer à literatura inglesa, na qual há o emprego de três conceitos das funções da política. São elas: polity, que faz referência às instituições políticas (partidos políticos); politics, que designa os processos políticos (política no sentido de governabilidade), e policy, para os conteúdos da política (programas e políticas públicas) (FREY, 2000, p. 217). O autor deixa claro que, para fins didáticos, essa diferenciação teórica é proveitosa; no entanto, é fundamental considerar que, na realidade política, essas dimensões são entrelaçadas e influenciam-se mutuamente.

Os estudos sobre políticas públicas buscam explicar a natureza das políticas e seus processos e não o conteúdo, dando as respostas no sentido de por quê e como. Já os estudos sobre as políticas sociais discutem o Estado do Bem-Estar Social, tendo o processo como pano de fundo, focando nas consequências da política, o que a política $f a z$ ou $f e z$, ou seja, procuram analisar as questões que a política busca resolver.

Segundo Höfling (2001, p. 31), "[...] políticas sociais se referem a ações que determinam o padrão de proteção social implementado pelo Estado". Tais ações devem estar voltadas à diminuição das desigualdades produzidas pelo sistema capitalista. Azevedo (2004, p. 5) explica que "[...] o conceito de políticas públicas implica considerar os recursos de poder que operam na sua definição e que têm nas instituições do Estado, sobretudo na máquina governamental”.

As políticas públicas configuram um conjunto de ações coletivas, interdependentes, associadas a decisões governamentais e de seus representantes, e são formuladas em diversas áreas, tais como: defesa, saúde, educação, previdência social, etc. (DUNN, 1994, p. 70 apud ESPINOZA, 2009, p. 3). Para Lanara Guimarães de Souza (2006), a política pública é uma estratégia cujo objetivo é desenvolver um determinado modelo econômico e social em todos os seus aspectos. A autora entende política pública como "[...] um fenômeno social e histórico que expressa os interesses de diversos sujeitos sociais, através do exercício do poder, baseado nos valores presentes da sociedade". (SOUZA, L. G., 2006, p. 9)

Na concepção gerencialista do Estado, Shiroma, Moraes e Evangelista (2004) explicam que as políticas públicas, em especial as políticas de caráter social, como é o caso da política de cotas, são caracterizadas por lutas, pressões e conflitos, 
que acontecem no interior dos grupos sociais. Isso mostra que as políticas não são estáticas; ao contrário, são empregadas de maneira estratégica na trajetória dos conflitos sociais, expressando a capacidade administrativa e gerencial para implementar decisões de governo. No caso brasileiro, a política de cotas não foi imposta pelo governo, mas pelas Instituições de Ensino Superior (IES), assumindo as lutas de grupos e de movimentos sociais em favor dos direitos de classe e de etnia. Estas buscaram a implantação de tais políticas considerando a realidade social da localidade onde estão inseridas, com vistas a proporcionar a igualdade real aos menos favorecidos.

Shiroma, Moraes e Evangelista (2004, p. 8) afirmam que as políticas públicas têm importância estratégica no Estado capitalista - sistema econômico vigente -, pois "[...] revelam as características próprias da intervenção de um Estado submetido aos interesses gerais do capital" ao mesmo tempo em que asseguram a cooperação e o controle social.

Para autores como Peroni (2003) e Azevedo (2004), as políticas públicas são partes constituintes das mudanças no papel do Estado, não sendo essas mudanças determinadas pelas políticas, mas as mudanças agem dando visibilidade e materialidade às políticas e ao próprio Estado.

Bucci (2006, p. 14, grifo do autor) define política pública como “[...] um programa ou quadro de ação governamental, porque consiste num conjunto de medidas articuladas (coordenadas), cujo escopo é dar impulso, isto é, movimentar a máquina do governo". A autora explica que as políticas públicas emanam do Estado e podem ser colocadas não só na forma de lei, mas de documentos legais diversos: "[...] disposições constitucionais, ou em leis, ou ainda em normas infra-legais, como decretos e portarias e até mesmo em instrumentos jurídicos de outra natureza, como contratos de concessão de serviço público, por exemplo". (BUCCI, 2006, p. 11)

Decretos, resoluções e portarias, embora não se caracterizando como uma lei, têm as mesmas prerrogativas desta para implantação e implementação das políticas e dos programas. Os envolvidos é que farão com que a política pública desenvolvase, aconteça efetivamente na sociedade. Daí a importância de considerar-se que as políticas públicas têm vida, pois se constituem em um processo dinâmico, com negociações, pressões, mobilizações, alianças ou coalizões de interesses (MAINARDES, 2006). É possível detectar modificações em uma política, fruto de discussões, interesses e até mesmo amadurecimento dos implementadores, 
dos sujeitos e da própria realidade em que a política foi implementada. São essas forças que atribuem vida, melhorias e ajustes que podem ser benéficos - ou não - para a população alvo da política.

As políticas públicas estão em constante movimento dialético, devido à negociação de seus implementadores e executores. "As ações empreendidas pelo Estado não se implementam automaticamente, mas têm movimento, têm contradições e podem gerar resultados diferentes dos esperados" (HÖFLING, 2001, p. 35). Isso acontece pelo fato de as políticas públicas estarem voltadas, especialmente, a grupos diferentes, sofrendo o seu impacto, interesse expresso nas diferentes classes e nas relações de poder.

Santi e Lima (2006), nessa mesma perspectiva, falam sobre a implementação das políticas públicas pelos sujeitos envolvidos no processo, pessoas que, positiva ou negativamente, envolvem-se e deixam envolver, delineando os caminhos. As autoras entendem que o Estado implanta as políticas, mas que são os sujeitos que, em última instância, as implementam no dia a dia, mediante as práticas cotidianas, e que, por questões de ordem objetiva e subjetiva, "[...] não correspondem com exatidão aos encaminhamentos traçados pelas políticas emanadas do Estado" (SANTI; LIMA, 2006, p. 263). É fundamental ressaltar, assim, que, para a elaboração e a implantação de uma política pública, é necessário considerar-se a natureza do regime político, o grau de organização da sociedade civil e a cultura política vigente.

Para ampliar a compreensão do complexo campo em discussão, Höfling (2001) faz uma distinção entre Estado e Governo, sendo definido o primeiro como um conjunto de instituições permanentes, órgãos legislativos, executivos e judiciários. Esses órgãos agem de forma a possibilitar a ação do Governo, que a autora define como o conjunto de programas e projetos, o qual assume e desempenha o papel de Estado por um determinado período de tempo. A autora compreende as políticas públicas como o Estado em ação, ou seja, “[...] é o Estado implantando um projeto de governo, através de programas, de ações voltadas para setores específicos da sociedade". (HÖFLING, 2001, p. 31)

Nessa perspectiva, as políticas públicas são diretrizes traçadas por um governo para o desenvolvimento de um determinado setor da sociedade. Também podem ser designadas como um conjunto de ações desencadeadas pelo Estado que determinam como serão utilizados os recursos públicos. Nesse contexto, há também uma distinção entre políticas de Estado e políticas de governo. Bucci 
(2006, p. 19) explica que "[...] há políticas cujo horizonte temporal é medido em décadas - são as chamadas 'políticas de Estado' -, e há outras que se realizam como partes de um programa maior, que são as ditas 'políticas de governo"”. Lanara Guimarães de Souza (2006, p. 9) caracteriza as políticas governamentais como o "[...] conjunto de programas elaborados no espaço restrito das instituições governamentais, configurada na interpretação feita pelos gestores públicos dos interesses e necessidades da população".

Quando analisadas as políticas públicas, é possível detectar que estas têm por objetivos uma referência valorativa, de forma a exprimir as diferentes opções e visões de mundo daqueles que estão no poder. Dessa forma, para legitimação das políticas, há a necessidade de contemplar os interesses dos diversos segmentos sociais envolvidos.

É importante entender esses conceitos para compreender que a política de cotas é uma política de Estado, pois tem objetivos de médio e longo prazo. Esta é uma política pública para diminuição das desigualdades, como uma possibilidade para evitar que estudantes de classes desfavorecidas continuem a se render ao sistema de (auto) exclusão social e educacional.

Avançando no debate sobre políticas educacionais, Höfling (2001, p. 31) entende política educacional "[...] como uma política pública social, uma política pública de corte social, de responsabilidade do Estado - mas não pensada somente por seus organismos". A autora complementa dizendo que, ao pensar as políticas públicas, ações pontuais são insuficientes para concretizar uma alteração de porte qualitativo no sistema educacional. É necessário, no momento do planejamento, discutir os resultados esperados pela efetivação da política pública. Daí a importância da avaliação da política e não somente a avaliação dos resultados da política pública.

A política educacional, tal como as relações estabelecidas nesse campo, pode ser tomada como um exemplo acerca do papel do Estado. As relações educacionais representam a concretização de uma série de relações estabelecidas com o intuito de efetivar uma política na qualidade de programa de ação (policy).

Para Lowi (apud SOUZA, C., 2006), as políticas públicas afirmativas, em especial as políticas de cotas, enquadram-se como políticas redistributivas. Essas políticas oferecem oportunidades a alunos de classes sociais desfavorecidas, dando igualdade de oportunidades de acesso ao nível superior de ensino em instituições públicas. Elas não são ideais, pois o ideal seria que todos tivessem 
oportunidades iguais, mesmo em diferentes contextos. Contudo, as cotas são necessárias, pois o capitalismo desenfreado agravou expressivamente a situação do grande número de pessoas que vivem à margem da sociedade (MORAES, 2009). "Em um mundo onde impera a lógica de que apenas alguns serão vitoriosos prevalece a ideia de que os que estão excluídos são culpados pelo seu fracasso". (MENDES, 2006, p. 174)

Mendes (2006) explica que os defensores do atual sistema econômico justificam sua posição pelo fato de que todos têm acesso à escola e que todos têm a oportunidade de estudar. Essa lógica do mercado acredita que "[...] os pobres são levados a arcar com a culpa de sua pobreza, pois não se esforçam para ter uma vida melhor" (MENDES, 2006, p. 174). A autora defende, ainda, que "[...] na medida em que uma política educacional constitui ação de um Estado comprometido com um setor da sociedade, pressupõe-se que essa ação acaba por fortalecer esse setor". (MENDES, 2006, p. 177)

Mészáros (2008) aponta a importância de resguardar que uma mudança educacional não se limite aos interesses do capital, pois isso significaria abandonar o objetivo da transformação social. As políticas afirmativas têm o objetivo de oferecer as oportunidades antes negadas a diversos setores da sociedade, diminuindo o abismo existente entre as classes sociais, pois, em educação, "[...] as soluções não podem ser apenas formais: elas devem ser essenciais". (MÉSZÁROS, 2008, p. 35)

\section{Democratização, justiça social e igualdade no estudo de uma política de cotas}

A política de cotas é uma política que se baseia no argumento de que a subrepresentação de minorias em instituições e posições de maior prestígio e poder na sociedade é um reflexo da discriminação. Esta visa, em caráter provisório, à criação de incentivos a grupos desfavorecidos para beneficiar os alunos que provêm de camadas populares, com baixo poder econômico, geralmente oriundos de escolas públicas, ou minorias étnicas, destacando o fato de que, muitas vezes, esses alunos têm necessidades específicas para sua integração e permanência nos espaços universitários.

A política de cotas vem ampliando o acesso de estudantes de classes desfavorecidas ao ensino superior. No entanto, para falar dos resultados de uma ação, é necessário antes compreendê-la, ou seja, considera-se fundamental esclarecer os elementos 
que embasam histórica e teoricamente tal política. Entende-se, ainda, que as políticas afirmativas são baseadas em conceitos fundamentais que justificam sua implantação e, neste artigo, tais elementos são: democratização, justiça social e igualdade.

Para Bobbio, Matteucci e Pasquino(2010), democracia converge em três tradições do pensamento político: teoria clássica, teoria medieval e teoria moderna. A teoria clássica é divulgada como teoria aristotélica, na qual Aristóteles diz que a democracia, como governo de todo o povo, diverge das diferentes formas de governo (monarquia e aristocracia). Na teoria medieval, originada na sociedade romana da antiguidade, o poder deriva do povo e se transmite por delegação do superior para o inferior. Quanto à teoria moderna, originada em Maquiavel, concebe-se que existem somente duas formas de governo, a monarquia e a república, sendo a democracia mais uma forma de república.

As discussões travadas sobre democracia política, ao longo dos séculos, envolveram, principalmente, um paralelo entre as duas doutrinas políticas dominantes: o liberalismo e o socialismo.

Considerando, de um lado, o modo como doutrinas opostas a respeito dos valores fundamentais doutrinas liberais e doutrinas socialistas consideraram a Democracia não incompatível com os próprios princípios e até como uma parte integrante do próprio credo, é perfeitamente correto falar de liberalismo democrático e de socialismo democrático, e é crível que um liberalismo sem Democracia não seria considerado hoje um "verdadeiro" liberalismo e um socialismo sem Democracia, um "verdadeiro" socialismo. (BOBBIO; MATTEUCCI; PASQUINO, 2010, p. 326)

Dessa forma, pode-se afirmar que a democracia acomoda-se a doutrinas com conteúdos ideológicos diversos, pois “[...] certamente nenhum regime histórico jamais observou inteiramente o ditado de todas estas regras; e por isso é lícito falar de regimes mais ou menos democráticos" (BOBBIO; MATTEUCCI; PASQUINO, 2010, p. 327).

Duriguetto (2007, p. 33) afirma que existe um limite da democracia no liberalismo: “[...] a sua existência só é compatível com ordenamentos políticos democráticos restritos cuja restritividade impede a transformação da igualdade formal em igualdade real". Bobbio, Matteucci e Pasquino (2010) explicam que a democracia no Estado socialista representa um elemento integrante e necessário, mas não 
constitutivo. Integrante, por ser esta uma das metas propostas pelos teóricos do socialismo; necessário, porque sem a democracia a profunda transformação da sociedade, tão desejada pelos teóricos, não seria alcançada, e não constitutivo, porque a essência do socialismo sempre foi a revolução de classes, a modificação das relações econômicas e não apenas das relações políticas, da emancipação social no plano formal.

No liberalismo, a democracia é tida como censitária, elitista, uma extensão do mercado, e esse sistema reage com relação à democracia. Para Bobbio (1988 apud PANSARDI, 2010, p. 81), "[...] a democracia moderna, assim, não foi fruto do movimento liberal”. Segundo o autor, o Estado liberal clássico não pode ser considerado democrático quando se observam os ideais da participação popular nas decisões que influenciam a sociedade, entrando esta em crise, para os liberais, justamente pela ampliação do Estado e das políticas públicas.

Nessa perspectiva, o surgimento do neoliberalismo é uma reação contra o advento da democracia das massas e da ampliação das políticas sociais (PANSARDI, 2010). Os neoliberais, que se declaram democráticos, não hesitam em apontar que as decisões do mercado estão acima das decisões políticas. "Restringir a democracia não significa restringir a liberdade, ao contrário, muitas vezes as decisões majoritárias limitam as liberdades, principalmente as das minorias" (PANSARDI, 2010, p. 84). Contudo, essa limitação não é percebida pelas minorias. A democracia é camuflada com preceitos de igualdade, de forma que as massas acabam abrindo mão da verdadeira liberdade.

Cury (2002) afirma que, de qualquer forma, o Estado é invocado como provedor do direito à educação, tendo a democracia, nesse contexto, a legislação como suporte. Esse direito deve garantir a igualdade de oportunidades, bem como intervir nas desigualdades oriundas pelos conflitos capitalistas de distribuição de renda. A política de cotas pode ser considerada uma política democrática, já que facilita a socialização de um bem - o Ensino Superior - para quem não tem chances iguais para concorrer a esse nível de ensino. No entanto, a democratização do acesso ao Ensino Superior é apenas um instrumento para se atingir a democracia plena, pois, conforme Duriguetto (2007, p. 50), “[...] as conquistas democráticas formais não devem ser a meta final das lutas dos trabalhadores", pois a democracia é apenas um dos instrumentos necessários para a verdadeira socialização. É necessário, assim, mais do que democratização. É necessário, igualdade. Em se tratando de política de cotas, é fundamental garantir o direito à igualdade e o direito à diferença. Para Cury: 
A dialética entre o direito à igualdade e o direito à diferença na educação escolar como dever do Estado e direito do cidadão não é uma relação simples. De um lado, é preciso fazer a defesa da igualdade como princípio de cidadania, da modernidade e do republicanismo. A igualdade é o princípio tanto da nãodiscriminação quanto ela é o foco pelo qual homens lutaram para eliminar os privilégios de sangue, de etnia, de religião ou de crença. Ela ainda é o norte pelo qual as pessoas lutam para ir reduzindo as desigualdades e eliminando as diferenças discriminatórias. Mas isto não é fácil, já que a heterogeneidade é visível, é sensível e imediatamente perceptível, o que não ocorre com a igualdade. Logo, a relação entre a diferença e a heterogeneidade é mais direta e imediata do que a que se estabelece entre a igualdade e a diferença. (CURY, 2002, p. 255)

Bobbio (2000, p. 10) explicita que, quando se afirma que todos são iguais, é necessário especificar outras questões, como, por exemplo, "[...] com que entes estamos tratando e com relação a que são iguais, ou seja, é preciso responder a duas perguntas: a) igualdade entre quem? e b) igualdade em quê?".

Para Winch e Gingell (2007), o conceito de igualdade está intimamente associado ao conceito de justiça, e uma vez que uma das preocupações da educação é a justiça, a igualdade e a educação estão intimamente ligadas. Para os autores, a igualdade pode existir como justiça processual, "“...] assim, todos os acusados têm direito de receber um julgamento justo, todos os cidadãos em uma democracia têm direito ao voto, todos os estudantes têm direito a uma avaliação adequada" (WINCH; GINGELL, 2007, p. 133). Contudo, isso não quer dizer que todos devem receber o mesmo tratamento.

Os autores destacam, ainda, que, para a igualdade de tratamento, os membros de um mesmo grupo devem ser tratados da mesma forma, sem segregação. Mesmo que seja comum afirmar que a igualdade de tratamento acarrete em uma igualdade de resultados, essa afirmação só é verdadeira quando parte-se do princípio de que todos os membros do grupo sejam iguais nos aspectos mais relevantes. Existe, também, o conceito de igualdade de oportunidade, que, para o princípio liberal, é semelhante à justiça processual. Defensores dessa linha dizem que "[...] para que ele seja significativo, os recursos devem ser equalizados entre os indivíduos, se houver resultados desejáveis". (WINCH; GINGELL, 2007, p. 134) 
Outra vertente, mais crítica, sustenta que a igualdade de resultados apresenta um terreno em que se pode presumir que as oportunidades não são iguais para todos os cidadãos. "Nessa interpretação do princípio, os resultados iguais deveriam ser projetados e construídos por meio da provisão de tratamentos desiguais". (WINCH; GINGELL, 2007, p. 134)

De acordo com Crahay (2002), a ideologia da igualdade de oportunidades é elitista; no entanto, quando vem acompanhada pela preocupação com a igualdade dos resultados, conduz a medidas de democratização do ensino. Este é um dos papéis das políticas afirmativas: democratizar as oportunidades de acesso ao Ensino Superior e promover a igualdade entre os cidadãos.

Em educação, a questão da igualdade liga-se à justiça social, e a discussão toma corpo, pois diferentes contextos atuam em diferentes concepções de justiça (WINCH; GINGELL, 2007). Uma das grandes questões que permeiam as políticas afirmativas, neste caso específico da adoção da política de cotas, é de como justificar tais políticas perante uma sociedade que, não raramente, busca justificativas para a manutenção das desigualdades sociais.

Assim como os princípios de igualdade, liberdade ou democracia, a justiça é um fim social. No entanto, há uma diferença: estes outros conceitos, embora abstratos, podem ser verificáveis empiricamente. Já a justiça é um conceito normativo e não descritivo. Ao longo dos tempos, o termo 'justiça' foi comparado à legalidade, à imparcialidade, ao igualitarismo etc. Bobbio, Matteucci e Pasquino (2010, p. 661) mostram que, se tais afirmações fossem aceitáveis, seria possível, baseados em fatos, chegar a conclusões normativas, '[...] por exemplo, se 'justo' tiver o mesmo significado de 'igual' e, portanto, se uma determinada norma for igualitária, concluiremos logicamente que ela também é justa”.

Bobbio, Matteucci e Pasquino (2010) explicam que, quando se fala em justo ou injusto, no tocante ao tratamento de classes de indivíduos, trata-se mais do que é moralmente bom ou moralmente mau, mas ressaltam, ainda, que algumas práticas possam ser consideradas moralmente erradas, mas dificilmente são injustas. Daí o conceito de justiça estar diretamente ligado aos conceitos de direito e de moral.

Os autores fazem a distinção do conceito de justiça: justiça distributiva, considerada como aquela que trata da distribuição de bens materiais ou honrarias entre os que participam do sistema político, e justiça reparadora, aquela que trata de situações nas quais aquele que se sente ofendido pede a consequente reparação. 
A justiça reparadora pode ser, ainda, subdividida em justiça compensativa e corretiva: "[...] as primeiras referem-se a negócios privados e voluntários e têm como escopo reabilitar o equilíbrio abalado mediante compensação para com a parte ofendida" (BOBBIO; MATTEUCCI; PASQUINO, 2010, p. 662). Quanto à justiça corretiva, os autores dizem que se trata da punição dos culpados.

O princípio da justiça compensativa ou compensatória fundamenta a política de cotas, porque busca compensar aqueles sujeitos que foram historicamente excluídos (como os pobres, os negros, as mulheres, os homossexuais, etc.) das oportunidades de educação e emprego, assegurando-lhes direitos antes negados.

Em termos descritivos, existem a justiça formal e a justiça substancial. Para a justiça formal, “[...] as ações legítimas são ações justas no sentido restrito" (BOBBIO; MATTEUCCI; PASQUINO, 2010, p. 662), ou seja, uma ação é justa quando é permitida pelas leis, e injusta, quando desobedece às leis. Assim, é correto, para um juiz, tratar casos iguais de forma igual e os diferentes de formas diferentes. Os autores enfatizam que esses princípios são compreendidos no conceito de norma, e que as leis podem ser justas ou injustas.

Para se chegar à enunciação de princípios substanciais da Justiça, "[...] é necessário especificar quais as semelhanças e quais as diferenças de características pessoais que deveriam ser tomadas, como base de um tratamento semelhante ou diferenciado" (BOBBIO; MATTEUCCI; PASQUINO, 2010, p. 663). Nesse sentido, as normas de distribuição devem ser dadas ou impostas àqueles que, conforme as particularidades de cada caso, possuem - ou não - determinadas especificidades. Esse princípio é o que embasa a política de cotas e as ações afirmativas como um todo, pois aqueles que não possuem as condições necessárias para concorrer de forma justa com relação aos demais candidatos às vagas das instituições públicas de Ensino Superior recebem uma vantagem, que possibilita seu ingresso em um nível de ensino que antes lhes era negado.

Para autores como Duriguetto (2007) e Neves e Lima (2007), a justiça social concretiza-se na participação popular efetiva na política, ou seja, a justiça social é antes uma questão política. Fica clara a necessidade do esclarecimento sobre a questão de a justiça ser antes uma aplicação política e, por consequência, econômica. Isso leva à percepção de que a política de cotas é antes um fato político e econômico, e de que a justiça é um meio de justificação para sua adoção, tendo como um possível resultado o empoderamento de classes historicamente excluídas e a diminuição das desigualdades educacionais e sociais. 


\section{A política de cotas avaliada: com a palavra, os estudantes}

Os dados foram coletados por meio dos questionários aplicados para estudantes de 11 cursos de Graduação ${ }^{1}$, representativos dos Setores de Conhecimento da universidade. Para tratamento dos dados qualitativos, estes foram analisados segundo a metodologia do Discurso do Sujeito Coletivo (DSC) de Lefèvre, Lefèvre e Teixeira (2000), e Lefèvre e Lefèvre (2005a, 2005b, 2010). A proposta metodológica escolhida “[...] como técnica que visa à identificação e descrição de representações sociais presentes em uma dada formação sociocultural a propósito de um determinado tema que se pesquisa, procura recuperar o semelhante e o diverso próprio das Representações Sociais". (LEFÈVRE; LEFÈVRE, 2010, p. 30)

A metodologia tem os seguintes operadores: expressões-chave (ECH), que é a parte selecionada do depoimento, após sua transcrição, que melhor descreve ou representa seu conteúdo; ideia central (IC), também denominada categoria, é uma expressão linguística que descreve, de maneira mais sintética, o sentido ou os sentidos presentes nos depoimentos de cada resposta e, também, no conjunto de respostas de diferentes indivíduos, que apresentam sentido semelhante ou complementar, e Discurso do Sujeito Coletivo (DSC), propriamente dito, que é a reunião das $\mathrm{ECH}$ presentes nos depoimentos com a IC de sentido semelhante ou complementar.

Para desvelar se, na opinião dos estudantes cotistas, a política de cotas tem possibilitado (favorecido) a democratização do acesso ao Ensino Superior, foi proposta a seguinte questão: "Em sua opinião, a política de cotas tem possibilitado (favorecido) a democratização do acesso ao Ensino Superior?". Com relação à promoção da justiça social e da igualdade, eles responderam às perguntas: "Você considera que a política de cotas promove a justiça social elou corrige as injustiças sociais e étnicas?" " "Em sua opinião, a política de cotas promove a igualdade entre os cidadãos?".

Inicialmente, as respostas às questões foram analisadas isoladamente, a partir do depoimento integral dos acadêmicos. O segundo passo constituiu-se em identificar

\footnotetext{
${ }^{1}$ Como se buscou obter os depoimentos dos estudantes cotistas, foi fundamental selecionar os cursos que, além de possuírem grande número de estudantes ingressantes pela política de cotas, possuíssem outras características peculiares, tais como: cursos com condições específicas, como cursos integrais, historicamente elitistas, com maior concorrência nos concursos vestibulares e, em contrapartida, cursos noturnos com a maioria de alunos trabalhadores.
} 
e sublinhar, em cada uma das respostas, as expressões-chave (ECH), as quais originaram as ideias centrais (ICs) ou categorias oriundas dos depoimentos dos acadêmicos cotistas às questões acima propostas. Em seguida, a construção dos DSCs foi direcionada para a elaboração de discursos diferentes com unidades de sentido diversificadas sobre a democratização, a justiça e a igualdade social.

Para apresentar a síntese dos resultados, os discursos do sujeito coletivo estão organizados em três grupos, os quais contemplam a percepção dos acadêmicos sobre a possibilidade de democratização do acesso ao Ensino Superior e a promoção da justiça social e da igualdade, por meio da política de cotas.

\section{Democratização do acesso ao Ensino Superior}

Dos 166 depoimentos dos estudantes cotistas analisados sobre a democratização do acesso ao Ensino Superior, constatou-se que 75,4\% destes declararam que a política de cotas possibilita/favorece a democratização, 19,8\% que não democratiza e 4,8\% não opinaram. A análise das respostas, a partir da metodologia do DSC, possibilitou a construção de quatro DSCs sobre a possibilidade de democratização do acesso ao Ensino Superior por meio da política de cotas, segundo a opinião dos estudantes cotistas. São eles: $\mathrm{DSC}_{\mathrm{A}}-\mathrm{A}$ política de cotas possibilita a democratização, considerando as desigualdades sociais; $\mathrm{DSC}_{\mathrm{B}}-$ A política de cotas possibilita a democratização do acesso, considerando as desigualdades entre o ensino público e o privado; $\mathrm{DSC}_{\mathrm{C}}-\mathrm{A}$ política de cotas possibilita a democratização do acesso, mas é necessário investir na educação pública, e $\mathrm{DSC}_{\mathrm{D}}$ - A política de cotas não democratiza o acesso. Esses DSCs serão apresentados e discutidos na sequência.

Os depoimentos sobre democratização revelaram que há estudantes que consideram que a política possibilita a democratização, considerando-se as desigualdades sociais, as desigualdades entre o ensino público e o privado, e a necessidade de investir no ensino público; e outros estudantes consideram que a política não democratiza.

Sobre a questão da democratização do acesso ao Ensino Superior, Dias Sobrinho (2011) evidencia a relevância que as políticas afirmativas têm, atualmente, na sociedade, principalmente para as minorias. $\mathrm{O}$ autor revela que as classes mais pobres têm, em média, cinco anos de escolaridade, contra dez das classes mais ricas, "[...] mais de 14 milhões de analfabetos adultos, com mais de 25 anos, são um símbolo persistente do tradicional descuido do Estado e da sociedade, 
relativamente ao cumprimento do princípio da equidade em prol da diminuição da desigualdade por meio da educação" (DIAS SOBRINHO, 2011, p. 138). Nesse sentido, a política de cotas exerce uma função de extrema importância para a redução das desigualdades sociais, como desvelado no $\mathrm{DSC}_{\mathrm{A}}$ dos estudantes pesquisados.

- $\mathrm{DSC}_{\mathrm{A}}$ - A política de cotas possibilita a democratização, considerando as desigualdades sociais

Sim, a política de cotas possibilita a democratização, pois os estudantes que não possuem uma renda acima da média, os que não puderam frequentar cursos pré-vestibulares, encontraram acesso mais rápido ao ensino superior. Antigamente, observávamos o ingresso à universidade de pessoas de classe média e alta, mesmo sendo uma universidade pública. Hoje, a política de cotas possibilita uma igualdade de oportunidades. Descentraliza as classes mais elevadas, que geralmente tem uma melhor educação, o acesso aos cursos superiores, o que possibilita a democratização para todas as classes sociais e acaba dando uma maior chance de alunos mais carentes terem pelo menos vontade ou motivação para tentar cursar o ensino superior. Esta é uma importante forma de democratização, pois, em um país desigual, como o Brasil, ela favorece a inclusão de grupos que, historicamente, guardam resíduos de exclusão. A política de cotas favorece não só a democratização, mas a inclusão social destes alunos. Sem a política de cotas o número de acadêmicos negros e de escola pública era muito menor.

Os DSC $_{B}$ e DSC $C_{C}$ foram construídos a partir das percepções dos estudantes que declararam que a política de cotas favorece a democratização, em virtude da desigualdade entre a qualidade do ensino público e o privado. A afirmação de que a educação pública não oferece as mesmas condições de ensino e aprendizagem que as escolas particulares é o principal argumento presente.

Nos discursos, os estudantes participantes da pesquisa deixam claro que a política de cotas democratiza o acesso ao Ensino Superior, mas enfatizam que a política não tem o poder de mudar o sistema educacional atual tão excludente. Um dos principais aspectos a serem considerados para a democratização e a promoção da justiça social na educação superior é a ampliação das matrículas. No entanto, 
[...] as políticas de expansão do acesso só se efetivarão sob a condição de ter havido uma cobertura completa e com qualidade nos níveis educacionais precedentes, a começar pela pré-escola. Isso indica um obstáculo, cuja superação requer pesados investimentos públicos: é necessário empreender uma grande expansão da infraestrutura física das escolas de nível básico e, ao mesmo tempo, impulsionar vigorosamente a formação de mais bem preparados professores. (DIAS SOBRINHO, 2011, p.134)

A política de cotas exerce um papel fundamental para o acesso ao Ensino Superior neste momento histórico, mas a elevação da qualidade do Ensino Básico é um aspecto que necessita ser considerado para a democratização na educação superior.

- $\mathrm{DSC}_{\mathrm{B}}$ - A política de cotas possibilita a democratização do acesso, considerando as desigualdades entre o ensino público e o privado

Sim, com certeza a política de cotas possibilita a democratização. Em se tratando de cotas para a escola pública, os alunos têm o ensino prejudicado, os conteúdos na sua maioria não são todos passados, deixando os alunos menos preparados. Os alunos na realidade têm menor preparação para fazer o vestibular, visto que não tem como negar a desvantagem do aluno de escola pública quando presta vestibular. Quem veio de escola particular é mais preparado. Sendo assim, fica mais "justo", alunos de escolas públicas disputarem vagas entre si e não com alunos de escolas particulares. Acredito que equilibra o ensino no Brasil, pois também não teriam condições de pagar faculdade particular. Eu estudei em escola pública, confesso que as cotas me ajudaram e muito, pois meu ensino foi menos desenvolvido, senti dificuldades no início do curso. Ainda não iguala ao acesso das redes privadas de ensino, porém oportuniza que alguns sejam beneficiados, mas repito: esta não é a solução.

- $\mathrm{DSC}_{\mathrm{C}}$ - A política de cotas possibilita a democratização do acesso, mas é necessário investir na educação pública

Sim, de certa forma sim, a política de cotas possibilita a democratização, pensando no hoje melhorou. No meu ponto de vista, a cota para escola pública ajuda muito, pois muitos não têm dinheiro para pagar um cursinho, mas falta mesmo investir 
numa educação de base de maneira mais efetiva para que os estudantes entrem com o mesmo preparo que os estudantes de escolas particulares. É um erro pensar que apenas esse sistema resolverá o problema como um todo. É preciso trabalhar para que todos os estudantes tenham as mesmas chances para ingressar na universidade. Ao invés da política de cotas, deveríamos fortalecer o ensino fundamental, mas não podemos deixar a educação falha, que existiu até hoje, prejudicar os do presente, pois é nisso que se baseia a democracia.

Dias Sobrinho (2011) explica que ampliar o nível de escolaridade é interesse de toda a população e está nas agendas governamentais, não apenas por representar um direito social, mas porque representa uma estratégia para o fortalecimento econômico e aumenta a competitividade mercadológica. Considerando-se que a sociedade atual está globalizada e segue as regras neoliberais e de mercado, esses fins não podem ser ignorados nas agendas públicas.

Nesse sentido, a política de cotas representa a possibilidade de elevação dos níveis culturais da população, mas traz consigo um meio de sobrevivência e de sucesso no mundo do trabalho para sujeitos que tiveram suas oportunidades minoradas em razão de classe e/ou etnia. Embora não tenha ocorrido no Brasil uma discriminação nos moldes da que existiu nos Estados Unidos e na África do Sul, com relação aos negros, a exclusão brasileira ainda é muito grande. É uma espécie de, nas palavras de Oliven (2009), racismo cordial, que oculta uma forte e permanente discriminação social. A autora explica que essas discriminações acarretam privações de oportunidades e desigualdades sociais e educacionais, $o$ que reforça cada vez mais a exclusão de grupos historicamente desfavorecidos. Oliven (2009) destaca, ainda, que, no Brasil, as diferenças de renda entre classes sociais distintas são extremas, mas que existe um grupo da população que sofre uma dupla discriminação: a pobreza e a cor da pele. "Embora nem todos os pobres sejam negros e nem todos os negros sejam pobres, dados de estatísticas oficiais nos mostram como é grande o fosso que separa a população negra da branca na sociedade brasileira”. (OLIVEN, 2009, p. 68)

$\mathrm{O} \mathrm{DSC}_{\mathrm{D}}$ representa os estudantes que acreditam que a política de cotas não favorece a democratização do acesso, uma vez que potencializa a discriminação. Esse discurso é bastante enfático e demonstra que, apesar das cotas, o acesso não está ao alcance de todos os estudantes e não representa uma realidade ou uma oportunidade para os grupos sociais que mais necessitam. 
- $\mathrm{DSC}_{\mathrm{D}}-\mathrm{A}$ política de cotas não democratiza o acesso

Não, a política de cotas não democratiza nada e prejudica alguns, favorece a desigualdade. Não acredito que as cotas sejam uma forma de democratização, foi mais marketing do que realidade essa democratização. Separação entre cotistas e não cotistas não favorece uma democratização efetiva, tem feito com que os alunos se sintam inferiores ou superiores uns aos outros. Isso é discriminação. Não podemos chamar de democrático a discriminação gritada que é o processo de cotas. Acredito que a verdadeira democracia só ocorre realmente quando as condições de acesso são iguais para todos e não separados pelo ensino que possuem, todos devem competir em um vestibular de igual para igual, sem que haja favorecimentos. Existe uma segregação das classes e esse método pode ser facilmente burlado. Muitos se aproveitam, indevidamente, das condições das cotas, a grande maioria dos acadêmicos são de família de classe média alta, ou seja, alunos que tiveram mais oportunidade na formação. As vagas (número) são insuficientes para suprir a demanda. O que se entende por democratização deveria ser para todos e, hoje, no Brasil, só $15 \%$ dos brasileiros frequentam a universidade e destes uma pequena quantidade é cotista. Além de que a disputa tem sido muito acirrada quanto às notas de cotistas e não cotistas. Minimiza a exclusão, mas não soluciona.

\section{Promoção da justiça social}

Quanto à promoção da justiça social e/ou correção das injustiças sociais e étnicas por meio da política de cotas, dos 166 estudantes participantes da pesquisa, $39,8 \%$ declararam que sim, ou seja, acreditam que a política de cotas possibilita a correção das injustiças sociais e étnicas; $51,2 \%$ declararam que não, e $9 \%$ dos estudantes não opinaram. Por meio da análise das respostas, foi possível construir cinco DSCs: $\mathrm{DSC}_{\mathrm{E}}$ - A política de cotas corrige as injustiças sociais e étnicas; $\mathrm{DSC}_{\mathrm{F}}-\mathrm{A}$ política de cotas corrige apenas as injustiças sociais; $\mathrm{DSC}_{\mathrm{G}}$ - A política de cota corrige parcialmente, pois é uma ação isolada; $\mathrm{DSC}_{\mathrm{H}}-\mathrm{A}$ política de cotas não corrige as injustiças, e $\mathrm{DSC}_{\mathrm{I}}-\mathrm{A}$ política de cotas exerce a função de inclusão no Ensino Superior.

$\mathrm{O}_{\mathrm{DSC}}$ expressa que a política de cotas vem possibilitando a promoção da justiça social para sujeitos antes excluídos ou em vias de exclusão do sistema educacional. 
- $\mathrm{DSC}_{\mathrm{E}}-\mathrm{A}$ política de cotas corrige as injustiças sociais e étnicas

Sim, como vivemos em uma sociedade capitalista, onde a distribuição de renda não é homogênea, muitos adolescentes deixam a escola para trabalhar e com isso a educação fica para o futuro. Em contrapartida, há aqueles que vivem para estudar e isso gera uma diferenciação que será percebida no resultado final do vestibular. A política de cotas possibilita que todos tenham acesso ao ensino superior, levando em consideração os conhecimentos adquiridos ao longo do tempo. Por muito tempo, a questão étnica deixou muitos em desigualdade, e as cotas tratam de uma tentativa de correção. Através dessas novas oportunidades, a igualdade possa a fazer parte da educação. O modo pelo qual o aluno ingressa na universidade e consegue uma melhora de vida em razão de um emprego melhor fica mais destacado quando o acadêmico vem das classes mais baixas, mas essa justiça deveria ser aplicada durante todo o percurso estudantil de ensino fundamental e médio. As cotas funcionam como instrumento de inclusão social, pois proporciona aos estudantes uma chance de ter aquilo que seus pais não tiveram a oportunidade de ter. Quando a justiça social e étnica estiver de acordo com o que é justo a todos, não serão mais necessárias as cotas.

Para Maliska (2009), uma política justifica-se se estiver alcançando os resultados esperados; note-se que a análise desse discurso demonstra que, na opinião desses estudantes, a política de cotas vem alcançando seus objetivos.

Nos discursos $\mathrm{DSC}_{\mathrm{F}}$ e $\mathrm{DSC}_{\mathrm{G}}$, observa-se que os estudantes acreditam que a política de cotas promove somente a justiça social, em virtude do baixo poder aquisitivo que os estudantes de escola pública, em geral, possuem. Brandão (2005, p. 99) tem uma opinião muito próxima das afirmações contidas nesses discursos: “[...] o sistema de cotas para o acesso ao Ensino Superior brasileiro só tem sentido se tomar como critério a situação econômico-social dos possíveis beneficiados por essa forma de reserva de vagas”. O autor afirma que são necessários mais debates sobre o tema na sociedade.

Nos discursos, fica clara a ideia de que as cotas minimizam as diferenças sociais e étnicas, mas não corrigem as injustiças étnicas históricas ou promovem a justiça social. É possível observar, nesses discursos, que os estudantes utilizam 
as expressões contribuem, minimizam e atenuam, e sempre afirmam que outras ações são necessárias para que a justiça social seja efetivamente promovida para todos os cidadãos.

- $\mathrm{DSC}_{\mathrm{F}}$ - A política de cotas corrige apenas as injustiças sociais

A justiça social sim, mas étnicas não. Alunos de escola pública têm, durante a vida, menos privilégios do que os que estudam em escolas particulares, pois o ensino é diferente e todos no Brasil têm o mesmo ensino público, independente de cor ou raça. A cota para negros parece desnecessária, pois eles se adéquam como cotistas de escola pública. Estudantes de escola pública dificilmente irão conseguir concorrer com alunos de escola privada, pois não recebem a atenção e o ensino necessário do governo, então acredito que ele deve investir nas cotas para que todos tenham acesso ao ensino superior. Não é a cor de pele que faz o aluno estudar, as oportunidades não são diferenciadas devido à etnia. Pode até promover a justiça social no caso de cotas para escola pública, porém fazer a separação dos negros, em minha opinião, é uma forma de discriminação. A desigualdade está na qualidade do ensino e não na raça-etnia. Poderiam existir apenas cotas para estudantes de escola pública, onde o ensino é mais fraco do que o particular e dificilmente as pessoas que estudaram em escola pública poderiam pagar uma faculdade particular. Os negros também têm direito ao ensino público, então eles deveriam participar das cotas de escola pública.

- $\mathrm{DSC}_{\mathrm{G}}-\mathrm{A}$ política de cota corrige parcialmente, pois é uma ação isolada

Não sei se as palavras adequadas seriam promove ou corrige. Corrigir é difícil, mas atenua bastante. Ambas são no intuito de reparação, se considerarmos um país construído com o suor escravo. A meu ver fica difícil apagar um passado de trezentos anos de escravidão. A política de cotas é um primeiro passo, que está evoluindo ao longo do tempo, pois os estudantes de escola pública têm as mesmas chances de ingressar na universidade. Mas isso precisa ser acompanhado de outras iniciativas também, eu acho que o governo deveria investir na educação pública para que ela se igualasse a particular, para que não houvesse necessidade da criação dessa política. Iniciativas que devem vir 
do Estado e de parte da sociedade que superou estes pré-conceitos também. Contudo, muitos cidadãos ainda estão excluídos. As cotas minimizam essas diferenças, mas não as eliminam. Muitas ações são apenas "pano de fundo". A política de cotas, para mim, é um modo do governo mostrar que se importa com os marginalizados, mas é difícil através de uma "ajudinha" romper com anos de injustiças sociais e étnicas. A única forma de corrigir seria não haver necessidade de cotas, pois, apesar de entrar na faculdade, o aluno continua pobre. Também acho que pelo fato dos demais estudantes estarem desinformados sobre o assunto, isto gera uma polêmica maior. Esse tema vai muito além disso, envolve culturas e a particularidade de cada comunidade ou indivíduo, mas isso com o tempo está melhorando e os estudantes estão se conscientizando.

Os discursos revelam que, para os estudantes pesquisados, a política de cotas tem um papel fundamental, mas sozinha não tem condições de promover a justiça social historicamente negada para tantas pessoas. As políticas afirmativas, nessa perspectiva, têm o mérito de ampliar as oportunidades de acesso e abrandar as desigualdades sociais. "Entretanto, têm seus limites e riscos. A maior inclusão que promovem não consegue romper a estrutura verticalizada e desigual da sociedade. Melhoram as condições de vida de milhares de jovens, e isso é altamente positivo, porém não alteram radicalmente o panorama social polarizado". (DIAS SOBRINHO, 2011, p. 148)

$\mathrm{Os} \mathrm{DSC}_{\mathrm{H}}$ e $\mathrm{DSC}_{\mathrm{I}}$ evidenciam que, para os estudantes cotistas participantes da pesquisa, a política de cotas está mais próxima de democratizar o acesso ao Ensino Superior do que promover a justiça social. Além disso, eles apontam que as cotas evidenciam as diferenças sociais e étnicas.

- $\mathrm{DSC}_{\mathrm{H}}-\mathrm{A}$ política de cotas não corrige as injustiças

A política de cotas não interfere em nada na desigualdade social enfrentada por negros, acaba até por colocar algumas pessoas expostas ao ridículo, pois todos sabem que um negro pode muito bem ter até mais capacidade que qualquer pessoa e, até pelo que entendo, ele não é um ser humano à parte. Acho que nesse ponto só agrava a situação das injustiças étnicas e sociais por separar em grupos. Cotas são uma forma de aumentar mais o preconceito, já que esse tipo de cota acaba. 
- $\mathrm{DSC}_{\mathrm{I}}$ - A política de cotas exerce a função de inclusão no Ensino Superior

A cota não deveria ser vista como objetivo de corrigir injustiças, mas sim com o papel de integração. Ela não corrige, mas ameniza a falha do governo no investimento ao ensino público, apenas faz uma parte na questão de inclusão social. Acho o sistema de cotas uma afirmação do preconceito e uma ação corretiva para esconder a péssima educação básica, mas acho temporariamente necessária para possibilitar alunos de escolas públicas a serem competitivos no vestibular. Ela oferece oportunidade aos estudantes, possibilita condições de acesso, mas não pode corrigir o que está posto como um problema na sociedade. De certa maneira, torna-se um fator imprescindível para alguns casos que talvez jamais tivessem essa oportunidade. Ajuda a nivelar, mas nunca corrigir, não tem esse alcance. Tinha que começar e começou com as cotas. Que venham mais políticas de igualdade.

A promoção da justiça social só é possível se todos os estudantes tiverem uma educação de qualidade, seja no sistema público, seja no privado. Na opinião de autores como Dias Sobrinho (2011), Brandão (2005) e outros, embora as ações afirmativas contribuam para a redução das desigualdades, promover a qualidade do Ensino Básico é ponto fundamental para promoção da justiça social.

\section{Promoção da igualdade social}

Com relação à promoção da igualdade por meio da política de cotas, $41 \%$ dos estudantes pesquisados declararam que a política promove a igualdade; 50,6\% entendem que a política de cotas não promove, e 8,4\% dos estudantes não opinaram. A análise das respostas permitiu a elaboração de três DSCs: $\mathrm{DSC}_{\mathrm{J}}-$ A política de cotas contribui para a promoção da igualdade; $\mathrm{DSC}_{\mathrm{k}}-\mathrm{A}$ política

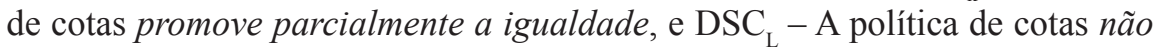
promove a igualdade.

$\mathrm{O} \mathrm{DSC}_{\mathrm{J}}$ revela que, para esses estudantes, a política de cotas pode contribuir para a promoção da igualdade, mas que uma ação afirmativa isolada não tem condições de promover a igualdade social. 
- $\mathrm{DSC}_{\mathrm{J}}$ - A política de cotas contribui para a promoção da igualdade

"Igualdade" é um termo muito forte. Promover a igualdade entre os cidadãos não passa apenas pelo mero acesso das cotas. Ela dá mais chances a quem não teve um ensino melhor de fazer universidade, de ter ensino superior, promove igualdade na concorrência, exemplo: alunos oriundos de escola pública competem com os que tiveram o mesmo nível de escolaridade, e alunos oriundos de escola particular competem com alunos de mesmo nível de escolaridade, embora as porcentagens de vagas para cada "categoria" não sejam iguais, poderia ser um nível adequado de vagas para cotistas. Acho que tem muita coisa bem mais importante que pode ser feito. Ela possibilita uma abrangência maior de acesso ao ensino superior, mas não garante uma sociedade mais igualitária. Só a política de cotas sozinha não promove a igualdade, depende de outras políticas sociais de promoção da igualdade e, principalmente, o fim do preconceito. Mais fatores precisam caminhar nesse sentido. A política de cotas proporciona uma oportunidade, mas para promover efetivamente essa igualdade social mais oportunidades em outros horizontes precisam acontecer. A igualdade possui uma amplitude que vai além da política de cotas, porém essa política favorece a inclusão, vai possibilitar oportunidades para as pessoas menos favorecidas que merecem, pois, mesmo sendo por cotas, ela passou por uma seleção que não é muito fácil. Quando as bases são fracas, a dificuldade aumenta. As cotas promovem sim uma igualdade de condições ao ingresso no ensino superior que, se devidamente trabalhado e aproveitado, pode promover certa igualdade entre os cidadãos. Igualdade eu não sei se é a palavra correta, pode ser que a política de cotas esteja "desencadeando" esse processo, mas o acesso ao ensino superior por si só não promove. São necessárias políticas de permanência, afinal são pelo menos quatro anos trabalhando, estudando, cuidando da casa e dos filhos. Mas, futuramente, poderá diminuir a desigualdade social no nosso país, disso eu não tenho dúvidas. É na verdade uma forma de melhorar um pouco as chances de crescimento das pessoas. Em tese, somos todos iguais, mas temos oportunidades diferentes. 
- $\mathrm{DSC}_{\mathrm{k}}$ - A política de cotas promove parcialmente a igualdade

Sim, para as cotas de escola pública, porque são pessoas que certamente não teriam chance de entrar, de ingressar no curso superior pelo universal. Acredito que o sistema universal e o sistema de cotas por escola pública são iguais, pois eles estão concorrendo com os seus mesmos. Agora a cota para negros promove a desigualdade, pois demonstra como se não tivessem a mesma capacidade dos outros. Neste caso, pode ser considerado como preconceito, já que muita gente tem as mesmas oportunidades, independente de cor de pele, eles são capazes como qualquer outra pessoa. Isso, muitas vezes, acaba se tornando motivo de desigualdade.

Nos discursos, ficou evidente que a política de cotas por si só, sem outras medidas substanciais anteriores, como equivalência de renda, e posteriores, como o acompanhamento, por exemplo, é insuficiente para promover a igualdade social. Para Felicetti e Morosini (2009, p. 13), as políticas afirmativas para acesso ao Ensino Superior podem ser positivas. As pesquisadoras consideram que "[...] políticas afirmativas para grupos específicos, também é uma forma que pode oportunizar a equidade de acesso ao Ensino Superior". Contudo, as autoras alegam que também é necessário garantir o sucesso aos estudantes, sugerindo maior atenção aos alunos por intermédio de acompanhamento, "[...] objetivando ajudar os alunos com risco de fracasso". (FELICETTI; MOROSINI, 2009, p. 13)

$\mathrm{O} \mathrm{DSC}_{\mathrm{L}}$ traz muitos elementos importantes para reflexão sobre a política de cotas, pois há estudantes que partilham da concepção de que as cotas enfatizam a discriminação, uma vez que todos os indivíduos são iguais e que questões como cor ou classe social não constituem elementos que devam representar favorecimento de condições para o ingresso no Ensino Superior.

- $\mathrm{DSC}_{\mathrm{L}}-\mathrm{A}$ política de cotas não promove a igualdade

É discriminação. Só porque existe a política de cotas podemos afirmar com certeza que não existe discriminação racial? É óbvio que não, pode até diminuir, mas promover totalmente a igualdade é hipocrisia. Mesmo com as cotas ainda há um desfavorecimento na classe dos alunos da rede pública. Isso reforça que os alunos cotistas são aqueles incapazes de adentrar numa faculdade e 
acaba segregando ainda mais. Ela apenas destaca essa diferença, pois se não fosse por elas os alunos competiriam de igual para igual. O aluno "cotista" é visto como beneficiário e não como promoção da igualdade. As cotas raciais são uma maneira de discriminação, uma maneira de dizer que você é diferente da maioria. Existem pessoas que entram sem muito esforço no ensino superior e, muitas vezes, tiram a oportunidade de quem realmente tinha direito.

A discriminação resulta sempre em desigualdade, afirma Piovesan (2005). Para que a desigualdade seja erradicada, é necessário garantir o pleno exercício dos direitos civis, políticos, sociais, culturais e econômicos. As ações afirmativas buscam garantir que esses direitos serão respeitados. "Nessa ótica determinados sujeitos de direito ou determinadas violações de direitos exigem uma resposta específica e diferenciada. [...]. Isso significa que a diferença não mais seria utilizada para a aniquilação de direitos, mas, ao revés, para sua promoção". (PIOVESAN, 2005, p. 46)

Para a autora, é fundamental que o respeito à diferença e à diversidade assegure um tratamento especial às classes desfavorecidas, como, por exemplo, aos alunos beneficiários da política de cotas nas universidades públicas. A autora afirma ser insuficiente o tratamento destinado, hoje, a essas classes, de forma genérica e abstrata, e enfatiza a necessidade de que esses sujeitos sejam vistos em suas particularidades. Em relação ao direito à igualdade e ao direito à diferença, a autora afirma que "[...] ao lado do direito à igualdade, surge também, como direito fundamental, o direito à diferença". (PIOVESAN, 2005, p. 47)

Após mais de um século de abolição da escravatura, é possível afirmar que a cidadania, no Brasil, caminha em duas velocidades distintas, que dependem da cor da pele e/ou da posição social na qual o sujeito está inserido (NEVES; LIMA, 2007). "Somente a partir das décadas de 1980 e 1990, os grupos antirraciais e movimentos negros ganharam mais força no Brasil e passaram a lutar pelos direitos antes negados e pela valorização identitária” (SANTOS, 2009, p. 75). Nesse contexto, os movimentos e os intelectuais em favor do negro puderam mostrar a necessidade de se refletir sobre os acontecimentos históricos, tirando os óculos da democracia racial ainda existente e de provar que as diferenças entre negros e brancos existem de fato, pois "[...] várias pesquisas feitas em sociedades nacionais distintas, demonstraram que o preconceito e a discriminação raciais dificultam a ascensão social de minorias étnicas ou raciais". (FERNANDES, 1972, p. 45) 
No entanto, defende-se que, além da igualdade de oportunidades, é indispensável a igualdade de resultados para que haja então uma igualdade efetiva entre os cidadãos. Bobbio (1996, p.128 apud CRAHAY, 2002, p. 39) afirma que quem acredita na igualdade está convencido de que a maior parte das desigualdades que provocam a sua indignação e que gostaria de ver desaparecer é de origem social e, por isso, elimináveis; entretanto, aquele que acredita na desigualdade pensa que é natural e, portanto, inevitável.

A educação é um direito de todos os homens; portanto, todo indivíduo deve ter as mesmas oportunidades de acesso à educação de qualidade e em todos os níveis de ensino.

\section{Considerações finais}

Ao se tratar da educação como elemento que possibilita a transformação da realidade social das pessoas, é preciso considerar-se frente a um tema profundamente complexo, amplo e desafiador. O fenômeno educativo envolve pessoas, contextos, necessidades, situações e exigências. Somam-se a isso as lutas e os embates situados no tempo e na história, as intervenções sociais e políticas, os valores e as crenças de cada sujeito, os avanços científicos e tecnológicos, as necessidades produtivas e econômicas, dentre outras tantas variáveis que intervêm direta ou indiretamente na educação.

Nesse sentido, o conhecimento científico construído no decorrer da história da humanidade serve como ponto de partida ao processo educativo, que é estruturado e permeado, também, pelas relações pessoais e sociais, pelas aspirações e intenções de cada ser humano envolvido com a educação. Assim, as pesquisas em educação devem buscar o aperfeiçoamento do fenômeno educativo, suas instituições, sua estrutura, suas políticas e seus resultados, em busca de uma sociedade mais democrática, mais igualitária e mais justa.

O objetivo da política de cotas é beneficiar aqueles sujeitos que, normalmente, não têm condições de acesso ao Ensino Superior. Essa ação afirmativa é necessária, pois, dificilmente, serão ampliadas em tão curto espaço de tempo as vagas em instituições públicas. Segundo Dias Sobrinho (2011), por questões de justiça social e desenvolvimento, é dever do Estado prover as condições para que a educação efetive-se como um bem social e, no cenário brasileiro, a expansão, a diversificação e o alargamento do sistema de educação superior vêm ocorrendo; no entanto, as instituições públicas não são o grande alvo dessa expansão. 
Considera-se que a justificativa para a política de cotas, nesse contexto, já é algo sentenciado como legítimo, postas as desigualdades brasileiras. No entanto, faz-se urgente compreender a avaliação da política de cotas como um processo inerente à implementação da política. Essas afirmações permitem que se compreenda a complexidade do tema.

Considerando-se essa problemática, os aspectos da política de cotas desvelados mostram que os estudantes da instituição pesquisada acreditam que a política de cotas da instituição pesquisada democratiza o acesso ao Ensino Superior; no entanto, eles acreditam que a política de cotas não promove a justiça social e/ ou corrige as desigualdades sociais e étnicas, quando afirmam que as cotas não promovem a justiça social sozinha, sendo necessário, concomitantemente, o desenvolvimento de outras ações de ordem macro, política e social. Para eles, a política de cotas não promove a igualdade entre os cidadãos, pois afirmam que a política de cotas não tem o poder de promover a igualdade, mas sim de contribuir para que esse processo ocorra.

As informações obtidas, neste trabalho, possibilitam afirmar que, de fato, uma política tem "vida": nasce, cresce, desenvolve-se. Nos DSCs, fica evidente como a implementação da política vem ocorrendo institucionalmente. Na análise dos discursos, é possível perceber o grau de efetividade da política implementada, com suas potencialidades e fragilidades. Os resultados obtidos neste trabalho de natureza qualitativa parecem demonstrar também que, ao mesmo tempo em que há a tentativa de reprodução das desigualdades sociais, há o processo oposto, de superação dessas relações desiguais. Quanto mais são acentuadas e elevadas as desigualdades, mais ocorre o movimento contrário, e a superação ganha espaço possibilitando transformações na realidade social, ainda que muito pequenas.

O movimento dialético das políticas públicas e da realidade é constante, e atinge a todos, sem distinção. Basta estar no mundo para sofrer as influências, quanto mais em uma sociedade globalizada. Nesse movimento, todos precisam buscar uma posição, definir opinião e traçar suas lutas.

Espera-se que esta pesquisa ofereça subsídios para ampliação dos estudos sobre política de cotas, contribuindo para a melhoria das condições de ingresso e de permanência de estudantes negros oriundos de escola pública e de estudantes oriundos de escola pública; para a criação de projetos institucionais que favoreçam a permanência dos estudantes no Ensino Superior; para o desenvolvimento de novas pesquisas acadêmicas sobre as políticas afirmativas, e para desencadear 
reflexões e discussões sobre a necessidade de se garantir a todo cidadão o direito à igualdade e o direito à diferença.

\section{Referências}

AZEVEDO, J. M. L. D. Educação como política pública. Campinas: Autores Associados, 2004.

BOBBIO, N. Igualdade e liberdade. Rio de Janeiro: Ediouro, 2000.

BOBBIO, N.; MATTEUCCI, N.; PASQUINO, G. Dicionário de política. Brasília: Editora UnB, 2010.

BRANDÃO, C. D. F. As cotas na universidade pública brasileira: será esse o caminho? Campinas: Autores Associados, 2005.

BUCCI, M. P. D. Políticas públicas: reflexões sobre o conceito jurídico. São Paulo: Saraiva, 2006.

CRAHAY, M. Poderá a escola ser justa e eficaz? Da igualdade das oportunidades à igualdade dos conhecimentos. Lisboa: Instituto Piaget, 2002.

CURY, C. R. J. Direito à educação: direito à igualdade, direito à diferença. Cadernos de Pesquisa, São Paulo, n. 116, p. 245-262, jul. 2002.

DIAS SOBRINHO, J. Educação superior: democratização, acesso e permanência com qualidade. In: DE PAULA, M. F. C.; LAMARRA, N. F. Reformas e democratização da educação superior no Brasil e na América Latina. Aparecida, SP: Ideia \& Letras, 2011. p. 121-152.

DURIGUETTO, M. L. Sociedade civil e democracia: um debate necessário. São Paulo: Cortez, 2007.

ESPINOZA, O. Reflexiones sobre los conceptos de "política", políticas púclias y política educacional. Archivos Analíticos de Políticas Educativas, Arizona, v. 17, n. 8, p. 1-13, abr. 2009. 
FELICETTI, V. L.; MOROSINI, M. C. Equidade e iniquidade no ensino superior: uma reflexão. Ensaio: Avaliação de Políticas Públicas em Educação, Rio de Janeiro, v. 17, n. 62, p. 9-24, jan./mar. 2009.

FERNANDES, F. O negro no mundo dos brancos. São Paulo: Difusão Europeia do Livro, 1972.

FREY, K. Políticas públicas: um debate conceitual e reflexões referentes à prática da análise de políticas públicas no Brasil. Planejamento e Políticas Públicas, Brasília, n. 21, p. 211-259, jun. 2000.

HÖFLING, E. D. M. Estado e políticas (públicas sociais). Cadernos Cedes, Campinas, v. 21, n. 55, p. 30-41, nov. 2001.

LEFÈVRE, F.; LEFÈVRE, A. M. C. Depoimentos e discursos: uma proposta de análise em pesquisa social. Brasília: Liber Livro, 2005a.

LEFÈVRE, F.; LEFÈVRE, A. M. C. O discurso do sujeito coletivo: um novo enfoque em pesquisa qualitativa (desdobramentos). Caxias do Sul: EDUCS, 2005b.

LEFÈVRE, F.; LEFÈVRE, A. M. C. Pesquisa de representação social: um enfoque qualiquantitativo. Brasília: Líber Livro, 2010.

LEFÈVRE, F.; LEFÈVRE, A. M. C.; TEIXEIRA, J. J. V. O discurso do sujeito coletivo: uma nova abordagem metodológica em pesquisa qualitativa. Caxias do Sul: EDUCS, 2000.

MAINARDES, J. Abordagem do ciclo de políticas: uma contribuição para a análise de políticas educacionais. Revista Educação e Sociedade, Campinas, v. 27, n. 94, p. 47-69, jan./abr. 2006.

MALISKA, M. A. Análise da constitucionalidade das cotas para negros em universidades públicas. In: DUARTE, E. C. P.; SILVA, P. V. B.; BERTÚLIO, D. L. L. Cotas raciais no ensino superior: entre o jurídico e o político. Curitiba: Juruá, 2009. p. 57-74.

MENDES, V. D. R. Reflexões sobre os conceitos de homem, liberdade e Estado em Marx e as políticas educacionais. In: PARO, V. A teoria do valor em Marx e a educação. São Paulo: Cortez, 2006. p. 157-178. 
MÉSZÁROS, I. A educação para além do capital. São Paulo: Boitempo, 2008.

MORAES, S. C. (Re)Discutindo a ação do estado na formulação e implementação das políticas educacionais. Educação, Porto Alegre, v. 32, n. 2, p. 159-164, maio/ ago. 2009.

NEVES, P. S. C.; LIMA, M. E. O. Percepções de justiça social e atitudes de estudantes pré-vestibulandos e universitários sobre as cotas para negros e pardos nas universidades públicas. Revista Brasileira de Educação, Rio de Janeiro, v. 12, n. 34, p. 17-38, jan./abr. 2007.

OLIVEN, A. C. Ações afirmativas na Universidade Federal do Rio Grande do Sul e o seu significado simbólico. Educação, Santa Maria, v. 34, n. 1, p. 65-76, jan./abr. 2009.

PANSARDI, M. V. Pensando as relações entre democracia e educação: do nascimento da social-democracia à hegemonia neoliberal. In: SCHLESENER, A. H.; SILVA, S. R. D. Política, gestão e história da educação no Brasil. Curitiba: UTP, 2010. p. 81-93.

PERONI, V. M. V. Política educacional e papel do Estado: no Brasil dos anos 1990. São Paulo: Xamã, 2003.

PIOVESAN, F. Ações afirmativas da perspectiva dos direitos humanos. Cadernos de Pesquisa, São Paulo, v. 35, n. 124, p. 43-55, jan./abr. 2005.

SANTI, A. P.; LIMA, A. B. D. As políticas curriculares no estado do Paraná nas décadas de 80 e 90: a concepção da escola sobre as políticas de currículo. In: SEMINÁRIO NACIONAL ESTADO E POLÍTICAS SOCIAIS NO BRASIL, 2., 2005, Cascavel. Anais... Cascavel: UNIOESTE, 2005. p. 1-9.

SANTOS, G. Relações raciais e desigualdade. São Paulo: Selo Negro, 2009.

ShIROMA, E. O.; MORAES, M. C. M. D.; EVAngelistA, O. Política educacional. Rio de Janeiro: DP\&A, 2004.

SOUZA, C. Políticas públicas: uma revisão de literatura. Sociologias, Porto Alegre, n. 16, p. 20-45, jul./dez. 2006. 
SOUZA, L. G. Política social e avaliação de políticas educacionais: construção de um referencial teórico. Formadores, Salvador, v. 1, n. 3, p. 1-15, 2006.

WINCH, C.; GINGELL, J. Dicionário de filosofia da educação. São Paulo: Contexto, 2007.

\section{Democratization, social justice and equality in the evaluation of an affirmative policy: the students' words \\ Abstract}

This article is part of a concluded Master's course research whose aim was to unveil whether the quota policy of an institution of Higher Education in Paraná state, Brazil, in the perception of the students who have resorted to it for admission in undergraduate courses, encourages or enables the democratization of access, promoting equality and social justice. Data were collected through a questionnaire and analyzed using the methodology of the Discourse of the Collective Subject (DCS). This text provides a brief discussion on social, public and affirmative policies, as well as on the quota policy. In the quota policy review, three concepts substantiate the discussion: democratization, equality and social justice. This study revealed that the quota policy can contribute to the democratization of access and the promotion of equality and social justice, provided that other actions or social policies are developed in parallel in society to ensure that every citizen has the right to equality and difference.

Keywords: Democratization. Equality. Social justice. Quota policy.

\section{Democratización, justicia social e igualdad en la evaluación de una política afirmativa: en palabras de los estudiantes}

\section{Resumen}

Este artículo es parte de una investigación de maestría ya concluida, cuyo objetivo fue averiguar si la política de cuotas de una institución de Enseñanza Superior paranaense favorece o posibilita el acceso democrático y promueve la igualdad y la justicia social, desde la perspectiva de aquellos estudiantes que intentaron ingresar en sus cursos de graduación. Los datos fueron recolectados a través de un cuestionario y se analizaron utilizando la metodología del 
Discurso del Sujeto Colectivo (DSC). El texto ofrece un breve análisis de la política social, pública, afirmativa y de cuotas. Al evaluar la política de cuotas la discusión se fundamentará sobre tres conceptos: democratización, igualdad y justicia social. El estudio reveló que la política de cuotas puede contribuir a la democratización del acceso junto con la promoción de la igualdad y la justicia social, a condición de que otras acciones o políticas sociales se desarrollen en paralelo en la sociedad, para así garantizar que todos los ciudadanos tengan derecho a la igualdad y a la diferencia.

Palabras clave: Democratización. Igualdad. Justicia social. Política de cuotas.

\section{Informações dos autores}

Andreliza Cristina de Souza: Professora do Departamento de Pedagogia da UEPG. Pesquisadora integrante do Grupo de Pesquisa em Políticas Educacionais e Avaliação, vinculado ao Programa de Pós-Graduação em Educação da Universidade Estadual de Ponta Grossa (UEPG) - PR. Contato: andrelizacsouza@gmail.com

Mary Ângela Teixeira Brandalise: Professora no Programa de Pós-Graduação em Educação - UEPG, e Coordenadora do Grupo de Pesquisa em Políticas Educacionais e Avaliação, vinculado ao Programa de Pós-Graduação em Educação da UEPG. 